\title{
Successful Endoscopic Resection of Tubulovillous Adenoma Arising in Choledochocele
}

\author{
Shin Hee Lee', Kyu-hyun Paik', Han Beol Jang', Jun Hyung Park', Jong Ok Kim², Won Suk Park' \\ 'Division of Gastroenterology and Hepatology, Department of Internal Medicine, 'Department of Pathology, Daejeon St. Mary's Hospital, \\ College of Medicine, The Catholic University of Korea, Daejeon, Korea
}

Choledochocele is the least common type of choledochal cyst. Choledochocele has a potential for carcinogenesis, but only a handful of cases with concurrent ampullary carcinoma have been reported. We recently experienced a case of choledochocele with tubulovillous adenoma with focal high-grade dysplasia, which was successfully and completely resected en bloc via endoscopic papillectomy. Prior to endoscopic papillectomy, the endoscopic ultrasonography was able to accurately diagnose the ampullary tumor arising in choledochocele. Herein, we would like to report this case and discuss the potential of malignant transformation and the usefulness of endoscopic ultrasonography in choledochocele.

Korean J Pancreas Biliary Tract 2021;26(1):58-62

Keywords: Ampulla of vater, Ampullary adenoma, Choledochal cyst, Endoscopic papillectomy, Endosonography

\author{
Received Mar. 16, 2020 \\ Revised Jul. 8, 2020 \\ Accepted Jul. 10, 2020
}

Corresponding author: Won Suk Park

Division of Gastroenterology and Hepatology, Department of Internal Medicine, Daejeon St. Mary's Hospital, College of Medicine, The Catholic University of Korea, 64 Daeheung-ro, Jung-gu, Daejeon 34943, Korea

Tel. +82-42-220-9331 Fax. +82-42-252-6808

E-mail; mdonekr@naver.com

ORCID: https://orcid.org/0000-0002-7194-7416
This is an Open Access article distributed under the terms of the Creative Commons Attribution Non-Commercial License (http:// creativecommons.org/licenses/by-nc/3.0/) which permits unrestricted non-commercial use, distribution, and reproduction in any medium, provided the original work is properly cited.

Copyright @ 2021 by The Korean Journal of Pancreas and Biliary Tract

\section{서 론}

총담관류(choledochocele)는 담관낭종(choledochal cyst) 중 가장 빈도가 낮은 질환이다. 일반적으로 담관낭종은 췌담관 합류이상과 동반되어 담도계암을 일으킬 수 있는 위험인자로 알려져 있으나 총담관류는 췌담관 합류이상이 동반되는 빈도가 낮고 악성 종양 발생에 대한 보고가 드물어 총담관류로 인한 악성 발생 가능성에 대해서 이견이 존재한다. ${ }^{1}$ 저자들은 상부위장관 검진에서 우연히 발견된 십이지장 유두부 종양으로
내원한 환자에서 내시경 초음파를 이용하여 유두부 종양이 총담관류 내에서 발생한 것으로 확인 후 내시경 유두절제술을 통하여 완전절제에 성공한 총담관류 내의 관상융모상 선종 1 예를 경험하였기에 문헌고찰과 함께 보고하는 바이다.

\section{증 례}

50 세 여자 환자가 건강검진으로 시행한 상부위장관 내시경 
검사에서 십이지장 유두부 선종으로 진단받고 검사 및 치료를 위해 소화기내과로 내원하였다. 환자는 입원 당시 어떤 증상도 호소하지 않았고 당뇨와 고혈압으로 투약 중이었으며 특이 가족력은 없었다. 혈압은 $150 / 70 \mathrm{mmHg}$, 맥박은 72 회/분, 호흡은 20 회/분, 체온은 $37.0^{\circ} \mathrm{C}$ 였다. 신체 검사에서 이상 소견은 관찰되지 않았다. 검사실 소견에서 말초 혈액 검사 소견은 백혈구 $9,500 / \mathrm{mm}^{3}$, 혈색소 $13.1 \mathrm{~g} / \mathrm{dL}$, 혈소판 $460,000 / \mathrm{mm}^{3}$, 혈청 생화학 검사 소견은 총 빌리루빈 $0.3 \mathrm{mg} / \mathrm{dL}, \mathrm{AST} 21 \mathrm{IU} / \mathrm{L}, \mathrm{ALT}$ 17 IU/L, r-GTP 43 IU/L, amylase 73 IU/L, lipase 49 U/L였다.

복부 전산화 단층촬영에서 십이지장 유두부 부근의 십이지장



Fig. 1. Abdominal computed tomography (CT) finding. Axial CT demonstrates $7 \mathrm{~mm}$ cystic structure within duodenal lumen (white arrow) and dilated common bile duct (black arrow) and pancreatic duct (arrow head) communicating with cyst.
벽 내에 약 $7 \mathrm{~mm}$ 의 낭성 병변이 발견되었고 췌관 및 담관의 확장이 동반되어 있었다(Fig. 1). 십이지장경 검사에서 십이지장 유두부 구측이 공기 흡인에 따라 부드럽게 들어가 함요 병변(Fig. 2A)으로 관찰되거나 풍선처럼 부풀어 오르는 팽윤 병변(Fig. 2B)으로 관찰되었으며, 유두부 입구에는 선종으로 진단된 종양이 관찰되었다(Fig. 2C). 내시경 초음파 검사에서 십이지장 유두부 근위부에 담관 및 주췌관과 연결되어 보이는 약 $15.5 \mathrm{~mm}$ 의 무에코성 낭종이 관찰되었고 낭종 내에 약

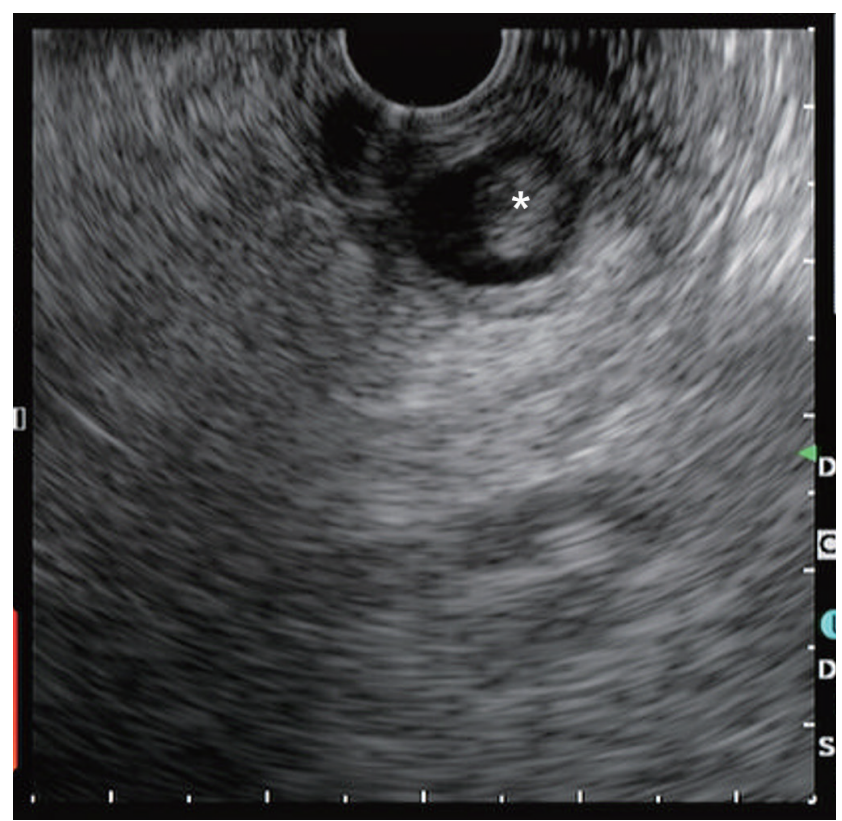

Fig. 3. EUS finding of major duodenal papilla. EUS shows that a cystic mass located in duodenal wall, proximal side of major duodenal papilla and that it contains a $7 \mathrm{~mm}$ polypoid mass (asterisk).
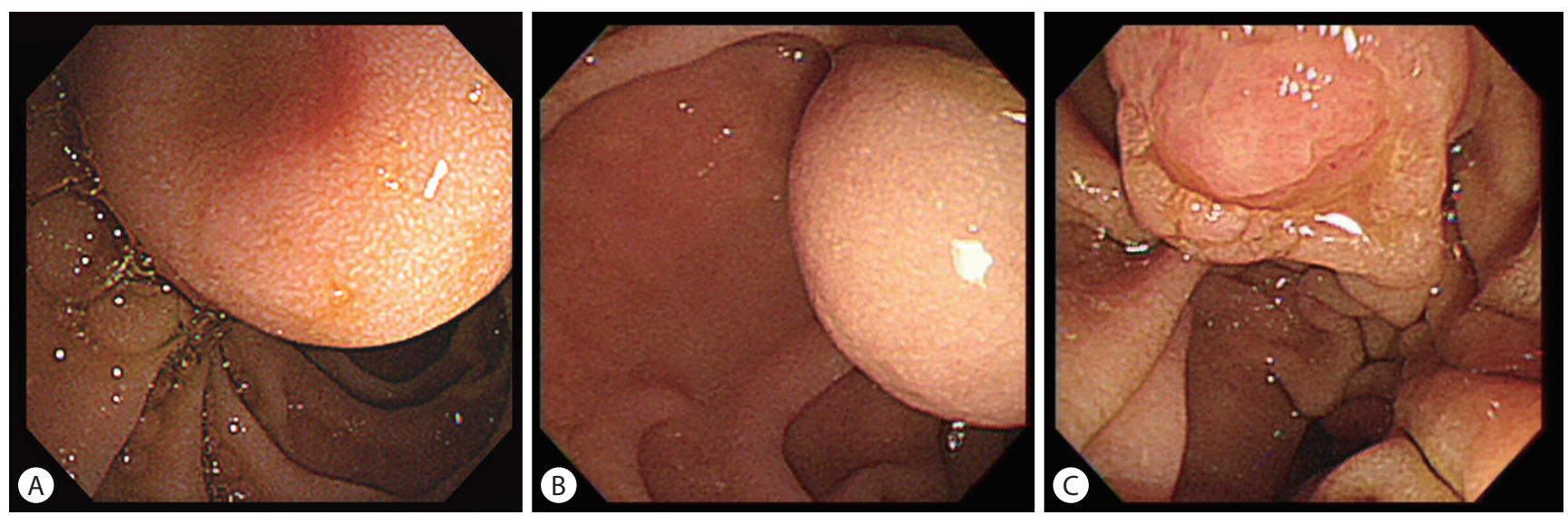

Fig. 2. Duodenoscopic findings of major duodenal papilla. Endoscopic view to proximal side of the papilla reveal (A) a cystic mass with dimpling and (B) balloon-like bulging depending on the air insufflation. (C) Endoscopic view of the papillary orifice shows the ampullary tumor. 
$7 \mathrm{~mm}$ 의 용종성 병변이 관찰되었다(Fig. 3). 저자들은 상기의 소견들을 종합하여 총담관류 내에서 발생한 십이지장 유두부 종양을 진단할 수 있었으며, 내시경 초음파에서 관찰되는 소견을 근거로 총담관류 및 종양이 내시경적 유두 절제술로 완전절제가 가능할 것으로 판단하였다.

십이지장 유두부 절제는 점막 하 주사 없이 통상적인 용종 절제용 올가미를 이용하여 근위부로부터 시작하여 개구부 아래의 일부 정상 점막까지 포함하여 일괄 절제하고, 담관 및 췌관을 선택 삽관 및 조영 후 각각에 플라스틱 배액관을 거치하였다(Fig. 4). 이후 환자는 혈색소 저하는 없었으나 병변의 관찰을 위하여 시행한 상부위장관 내시경에서 절제 부위에 혈관 노출과 출혈이 관찰되어 클립 지혈술을 시행하였다. 환자는 추가 출혈 및 합병증이 관찰되지 않아 식이 진행 후 퇴원하였다. 조직병리 검사에서 종양은 완전절제되었으며,
총담관류 내에서 발생한 일부 고도 이형성을 보이는 관상융모상 선종으로 최종 진단되었다(Fig. 5).

\section{고 찰}

담관낭종은 간외 담관 또는 간내 담관이 낭성 확장을 보이는 질환이다. 담즙 정체 및 췌담관 합류이상에 의한 췌액 역류로 담낭 및 담관암의 발생 위험을 높여 임상적으로 중요한 의미를 지닌다. ${ }^{1}$ 담관 낭종은 Todani 분류법에 따라 다섯 가지로 분류된다. 총담관 내로 구형 또는 방추형의 확장을 보이는 경우를 제 1 형, 총담관 내 게실 소견을 보이는 경우를 제 2 형으로 분류한다. 제3형은 원위부 총담관의 낭성 확장을 보이면서 십이지장으로 돌출된 경우를 말하며, 이를 총담관류라고 한다.
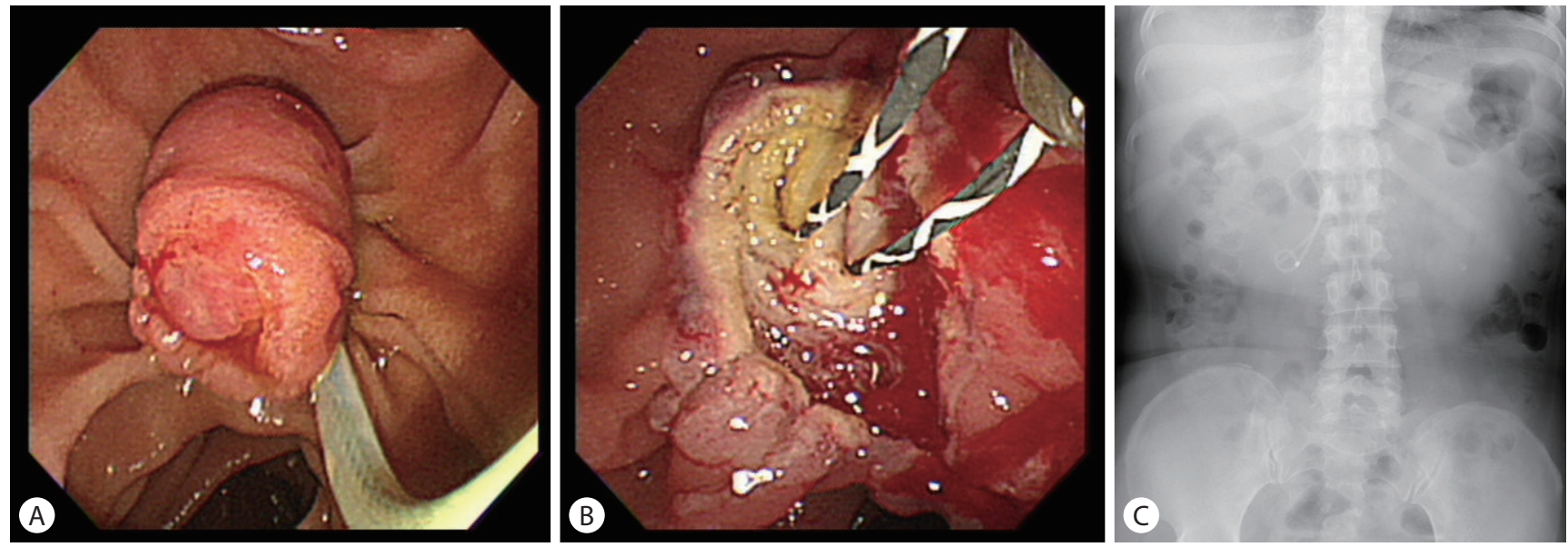

Fig. 4. Endoscopic and radiologic findings of papillectomy. (A) Ampullary adenoma with choledochocele is snared. (B) After resection, two guide wires are inserted into the pancreatic duct and common bile duct. (C) Abdominal X-ray shows two plastic stents in the bile duct and the main pancreatic duct.
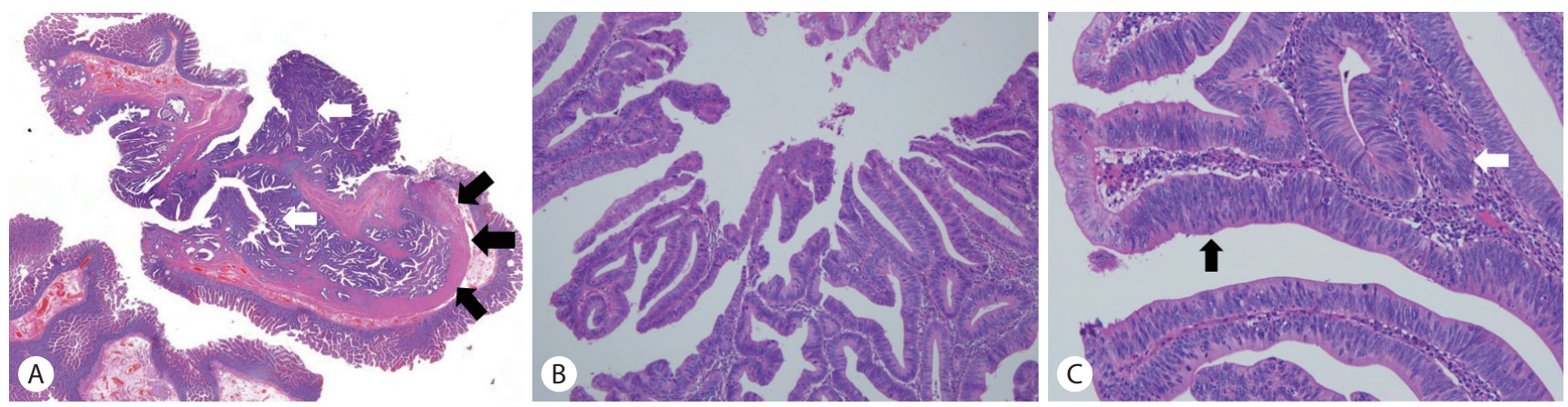

Fig. 5. Pathologic findings of ampullary adenoma. (A) Gross finding of endoscopic resected specimen showing choledochocele (black arrows) with tubulovillous adenoma arising in the choledochocele and extending to extra-papillary mucosa (white arrows) (H\&E, $\times 6$ ). (B) Intra-ampullary papillarytubular neoplasm shows predominantly $(>75 \%)$ papillary $(\mathrm{H} \& \mathrm{E}, \times 100)$ and $(\mathrm{C})$ tubular growth with low-grade (white arrow) to high-grade dysplasia (black arrow) $(H \& E, \times 200)$. 
제4형은 간내 담관과 간외 담관으로 다발성 확장이 있는 경우, 제5형은 간내 담관 낭종이 있는 경우를 말한다. ${ }^{2,3}$

총담관류는 Sarris와 Tsang의 분류법으로 해부학적 구조에 따라 $\mathrm{A}$ 형과 $\mathrm{B}$ 형군으로 나눌 수 있다. $\mathrm{A}$ 형은 총담관의 유두부가 낭성 병변 내로 개구하며 다른 개구부를 통해 십이지장으로 배출되는 형태이며, B형은 유두부가 십이지장 내로 직접 개구하며 낭성 병변은 총담관의 원위부에 게실 양상으로 돌출되는 형태이다. ${ }^{4}$ 총담관류 환자의 초기 증상은 다양하고 불분명하다. 상복부 통증과 구역, 구토가 생길 수 있으며, 신체 검진에서 간혹 복부 팽만, 압통 혹은 종괴가 만져진다. 질환과 관계없이 영상학적 검사에서 우연히 발견되는 경우도 있다. 가장 흔하게 호소하는 증상으로는 반복적인 복통과 황달이 있다. 담즙과 췌액의 배출장애로 췌관 내 압력이 증가하거나, 담즙액이 췌관으로 역류하여 급성 췌장염을 유발하는 것으로 알려져 있다. 총담관류 내 담석 또한 담즙의 만성적인 저류로 인해 발생하는 것으로 알려져 있다. Sarris와 Tsang의 보고에 따르면 총담관류 환자의 약 $25 \%$ 에서 담석을 동반하였고, $30 \%$ 의 환자에서는 급성 췌장염이 동반되었다. $2,5,6$

일반적으로 담관 낭종은 췌담관 합류이상과 동반하여 췌액이 담관으로 역류하며 만성적인 염증을 일으켜 담도계 암을 유발시키므로 수술적 치료를 요하는 것으로 알려져 있다. 하지만 총담관류는 췌담관의 합류이상을 동반하는 경우가 매우 적고 담도계 암의 발생이 매우 드물게 보고되고 있어서 악성화 가능성이 낮을 것으로 생각되고 있다. 그러나 발생률에 대해서는 아직 이견이 있다. ${ }^{1}$ Ladas 등 ${ }^{7}$ 은 연구에서 15 명의 총담관류 환자에서 1 명이 유두부 선암이 발생하였음을 관찰하여 발생률을 $2.5 \%$ 로 추정한 바 있다. 하지만 Ohtsuka 등 $^{1}$ 은 연구에서 11 명 중 3 명이 십이지장 유두부 선암을 동반하고 있어 발생 빈도를 $27 \%$ 까지 높게 보고하였다. Horaguchi 등은 21 명의 총담관류 환자를 분석하여 이전 연구와 다르게 담낭암 2 명(9.5\%), 담도암 1 명 $4.8 \%$ )만을 보고하였다. ${ }^{1,5-7}$ 하지만 이러한 연구들은 증상을 유발한 총담관류 환자에서 추정한 담도계 암의 발생 빈도이며, 또한 매우 적은 수의 증례로 총담관류 환자에서 유두부 종양의 발생률을 추정하는 데 한계점이 있다.

총담관류를 진단하는 데 여러 가지 영상학적 방법이 사용될 수 있는데, 그중 내시경 초음파는 총담관류의 진단뿐 아니라 이후 치료 방침을 정하는 데 도움이 된다. 내시경 초음파에서 총담관과 연결된 무에코성의 낭성 병변이 관찰되면 총담관류를 진단할 수 있으며, 내시경 초음파를 통해 병변 내의 담석, 종양
동반 여부 및 췌담관과 병변의 연결성을 확인할 수 있고 병변과 십이지장 근육층이 연결되었는지 확인할 수 있다. 십이지장 중복 낭종의 경우 십이지장 근육층과 병변이 연결되어 있어 내시경적으로 완전절제가 어렵기 때문에 수술적 치료를 시행하게 되는데, 이를 판단하는 데 내시경 초음파가 도움이 된다. ${ }^{2,8,9}$ 총담관류 확진 및 치료에 가장 결정적인 검사는 내시경역행담췌관조영술로 진단과 치료를 동시에 시행할 수 있다는 장점이 있다. 구형의 팽창된 유두부가 관찰되고, 낭종을 둘러싼 점막이 부드러우며 조영제를 주입하였을 때 유두부가 팽창되는 소견과 총담관 원위부와 연결된 낭종 양상의 소견을 보이면 확진할 수 있다. ${ }^{6,10}$

이전에는 총담관류를 치료하는 데 담관의 폐색을 호전시키고 전암성 병변의 가능성이 있는 조직을 제거하기 위하여 경십이지장 절제술 및 유두부 절개술 등의 수술적 치료를 먼저 고려하였다. 그러나 Deyhle 등 ${ }^{11}$ 이 1974년 처음 내시경적 치료술의 가능성을 보고한 이후, 현재는 대부분의 환자에 내시경적 치료가 기본 치료로 사용되고 있다. A형 총담관류에서는 내시경적 괄약근 절개술 또는 올가미절제술을 고려할 수 있으며, B형 총담관류에서는 올가미를 사용한 절제술이 필요하다. 총담관류 내에 유두부 선종이 동반된 경우 선종의 크기가 $3 \mathrm{~cm}$ 이내이며 조직 검사에서 선암의 증거가 없을 경우 내시경적 유두 절제술을 고려할 수 있다. 내시경적 유두 절제술은 선종 전체를 일괄절제로 완전 제거해야 하기 때문에 숙련된 내시경 의사가 시행하는 것이 필요하다. 병변이 완전절제가 가능할지 판단하고 병변의 변연을 찾아 확인하고 절제한다. 병변의 크기가 커 분할절제가 되는 경우 추가적인 절제술을 시행하게 된다. ${ }^{2,9}$ 저자들은 내시경 초음파를 통해 총담관류 내에서 기인한 십이지장 유두부 선종을 진단하고 올가미를 이용한 내시경 절제술을 통하여 완전절제에 성공한 관상융모상선종 1 예를 경험하여 보고하는 바이다.

\section{요 약}

총담관류는 담관낭종 중 가장 빈도가 낮은 질환으로 악성 종양 발생에 대한 보고가 드물어 총담관류로 인한 악성 발생 가능성에 대해서 이견이 존재한다. 저자들은 상부위장관 검진에서 우연히 발견된 십이지장 유두부 선종으로 내원한 환자에서 내시경 초음파를 이용하여 총담관류 내에서 발생한 선종으로 진단 후 올가미를 이용한 내시경 유두절제술을 
통하여 완전절제에 성공한 증례를 경험하였다. 이에 총담관류 내 악성 종양 발생 가능성 및 총담관류의 진단과 내시경적 치료에 대한 문헌 고찰과 함께 보고하고자 한다.

국문 색인: 십이지장 유두부 종양, 십이지장 유두부 선종, 총담관류, 내시경 유두 절제술, 내시경 초음파

\section{Conflicts of Interest}

The authors have no conflicts to disclose.

\section{REFERENCES}

1. Ohtsuka T, Inoue K, Ohuchida J, et al. Carcinoma arising in choledochocele. Endoscopy 2001;33:614-619.

2. Law R, Topazian M. Diagnosis and treatment of choledochoceles. Clin Gastroenterol Hepatol 2014;12:196-203.

3. Todani T, Watanabe Y, Narusue M, Tabuchi K, Okajima K. Congenital bile duct cysts: classification, operative procedures, and review of thirty-seven cases including cancer arising from choledochal cyst. Am J Surg 1977;134:263-269.
4. Sarris GE, Tsang D. Choledochocele: case report, literature review, and a proposed classification. Surgery 1989;105:408-414.

5. Horaguchi J, Fujita N, Kobayashi G, Noda Y, Ito K, Takasawa O. Clinical study of choledochocele: is it a risk factor for biliary malignancies? J Gastroenterol 2005;40:396-401.

6. Lobeck IN, Dupree P, Falcone RA Jr, et al. The presentation and management of choledochocele (type III choledochal cyst): a 40-year systematic review of the literature. J Pediatr Surg 2017;52:644-649.

7. Ladas SD, Katsogridakis I, Tassios P, Tastemiroglou T, Vrachliotis T, Raptis SA. Choledochocele, an overlooked diagnosis: report of 15 cases and review of 56 published reports from 1984 to 1992. Endoscopy 1995;27:233-239.

8. Bazerbachi F, Visrodia KH, Mavrogenis G, Topazian MD. The endosonographic appearance of a type-A choledochocele. Ann Gastroenterol 2020;33:102.

9. Espinel J, Pinedo E, Ojeda V, Guerra Del Río M. Endoscopic ampullectomy: a technical review. Rev Esp Enferm Dig 2016;108:271-278.

10. Kim MH, Myung SJ, Lee SK, et al. Ballooning of the papilla during contrast injection: the semaphore of a choledochocele. Gastrointest Endosc 1998:48:258-262.

11. Deyhle P, Schnaars P, Meyer HJ, Nüesch HJ, Akovbiantz A. Electrosurgical removal of a choledochocele through an endoscope introduced by mouth. Dtsch Med Wochenschr 1974;99:71-72. 